\title{
Editorial: A Delicada Escuta para a Narrativa do Futuro na Pós-Graduação em Psicologia
}

\author{
Fabio Scorsolini-Comin* \\ Universidade de São Paulo, Ribeirão Preto, SP, Brasil
}

\begin{abstract}
Talvez no tempo da delicadeza. (Cristóvão Bastos e Chico Buarque, Todo o sentimento, 1987).

A predestinação, longe de constituir uma condenação definitiva, é passível de interferências dentro de certos limites. Se assim fosse, Ifá não teria como epíteto de Aquele que adia a data da morte. O sistema oracular de Ifá, consultado por homens, por todos os Orixás e pelo próprio Orunmilá, orienta na condução de caminhos que aproximem da Verdade e do equilíbrio harmonioso de forças. (Ribeiro et al., 2004, p. 11).
\end{abstract}

Como assinalado deste o título, o presente texto costurase a partir de duas noções que serão tomadas de empréstimo nesse espaço: o futuro e a delicadeza. A orientação para o futuro é uma das questões que mais nos movem em nossa sociedade ocidental. Retomando as mitologias iorubás, em uma perspectiva próxima do que contemporaneamente temos assumido como sendo a Psicologia Africana ou Psicologia Afrocentrada (Nobles, 2009; Nogueira \& Guzzo, 2016), é preciso resgatar nossas ancestralidades, o que não pressupõe que não tenhamos qualquer curiosidade ou ansiedade pelo porvir. O Oráculo de Ifá, metaforizado por Ribeiro et al. (2004) para tratar do modo como o homem moderno tem se apresentado diante das noções de tempo, de pessoa e de destino, é empregado aqui para refletirmos sobre um futuro que se deseja vicejar.

Obviamente que essa fruição não é fragmentada, mas dialoga diretamente com nossas heranças e, de modo mais forte, com o nosso presente. Trazendo à baila essa perspectiva afrocentrada, podemos compreender que o desejo contemporâneo por desnudar o futuro é uma ruptura com o resgate à ancestralidade. Desse modo, reverenciar o passado não é um exercício exclusivamente histórico, mas se insere no próprio movimento de ruptura com uma
Psicologia ocidental, brancocêntrica e que vem sendo revista por leituras mais suleadas. Este texto, buscando reverenciar o passado, também se compromete com uma leitura de futuro para o qual nos preparamos enquanto pesquisadores, ávidos pela descoberta que orienta muitas de nossas buscas, projetos e intentos.

A segunda noção basal nessa proposta, a de delicadeza, é uma palavra que, por vezes, é retratada, sobretudo no campo da ciência psicológica, para recobrir uma série de experiências, fenômenos e relações que se apresentam ora como frágeis, ora como especiais, demandando do interlocutor um olhar, uma observação ou um contato que respeite uma condição de especificidade ou de vulnerabilidade. Falamos de delicadezas ao abordarmos assuntos considerados complexos e de difícil manejo, como no contexto da violência sexual (Lordello \& Costa, 2017) ou de jovens em situação de rua (Lima \& Morais, 2019). Falamos da delicadeza ao nos comunicarmos, por exemplo, com crianças e adolescentes em situação de vulnerabilidade (Rossetti-Ferreira et al., 2010). Falamos de delicadeza ao abordarmos cenários de transição que não nos permitem refletir, com segurança, quais caminhos podem ser trilhados e como o futuro pode ser conjugado. A delicadeza atravessa o que é preciso ser tocado com cautela ou, melhor dizendo, com cuidado.

O cuidado é um elemento que entrelaça diferentes conhecimentos profissionais. Nas ciências humanas, sociais e da saúde, é o cuidado que costura relações e desperta para a necessidade de que essas áreas dialoguem entre si para pensarem melhores formas de tratar, de medicar, de intervir, de aproximar, de estar, de ser, de tocar. O cuidado não pode ser promovido em sua plenitude e de modo humanizado se esses profissionais não se atentarem para a delicadeza

*E-mail: fabio.scorsolini@usp.br 
presente nessa relação. E é por nos mobilizarmos com essa delicadeza que nos propomos, enquanto pesquisadores, a nos engajarmos nessa reflexão e a permitirmos que também nossos alunos mergulhem nesse campo discursivo polissêmico e polifônico que constitui a promoção do cuidado e a sua narrativa.

Nossos recursos para esse cuidar muitas vezes mostramse limitados, o que dispara a necessidade de produzirmos alternativas e inteligibilidades capazes de suprir hiatos e desfechos considerados inadequados. Trazemos à baila, então, a metáfora do delicado quando precisamos empregar recursos para além dos quais já estamos acostumados em nossa prática clínica ou mesmo na pesquisa. $\mathrm{O}$ delicado, nesse caso, aproxima-se de noções clássicas como as de complexidade (Morin, 2000) e de subjetividade (González Rey, 2007), ambas muito próximas da ciência psicológica. Mas voltemos ao desafio de cuidar e de pensar o cuidado, o que pode e deve ser considerado quando analisamos a formação de novos pesquisadores e de novos docentes. A formação de recursos humanos alinhados a esses pressupostos nos conduz inequivocamente para a pós-graduação.

A pós-graduação em nosso país deve ser compreendida como um campo em expansão, fruto de investimentos em pesquisa e em formação qualificada de novos pesquisadores e novos docentes para o ensino superior ao longo dos últimos anos. Em que pese a complexa estrutura que sustenta a pós-graduação no Brasil e a diversidade que atravessa as diferentes áreas do conhecimento, não podemos nos furtar à consideração de que esse cenário é igualmente delicado. Olhando (ou escutando) mais detidamente esse contexto, importantes reflexões tornam-se prementes.

Nos últimos anos, o número de cursos de pósgraduação em Psicologia em nosso país tem se ampliado quantitativamente, o que vem sendo acompanhado pelo desafio de qualificar esses programas também de modo crescente, possibilitando maior diálogo com a produção internacional e agregando elementos que permitam não apenas uma formação adequada, mas que esteja comprometida com o avanço do conhecimento científico e de práticas profissionais que se alinham ao complexo cenário político, educacional e cultural que nos constitui e que está em constante revisão (Bastos et al., 2015; Costa et al., 2014; Costa \& Yamamoto, 2017; Féres-Carneiro et al., 2010). Na contemporaneidade, tais debates devem ser cotejados diante das instabilidades políticas que também afetam a pós-graduação, exigindo posicionamentos críticos e de resistência. $\mathrm{O}$ cenário delicado que se desenha reflete esse movimento, que muitas vezes se sustenta em um ir-evir que também se revela importante para reflexões várias.

Comprometidos com esse campo de instabilidades, os programas de pós-graduação em Psicologia têm se alinhado à necessidade de não apenas cumprir as métricas planejadas, mas também de inovar para além desses aspectos, tanto em termos científicos como da formação de profissionais porosos a essa complexidade. Assim, a docência no ensino superior, por exemplo, passa a ser um campo de especial atenção. De que modo a pós-graduação tem contribuído para a formação de novos docentes? Quais os recursos que a pós-graduação tem oferecido a esses profissionais, egressos de seus programas? (Souza \& Scorsolini-Comin, 2017). Essas perguntas não podem ser respondidas sem que se retome a missão de cada programa e a quais ideários esse sistema busca responder. Sob a égide de um diálogo interdisciplinar e abarcando as complexidades - e também as delicadezas - da clínica em Psicologia é que pretendemos discorrer a partir daqui.

Neste texto, emprego a delicadeza para falar da escuta que atravessa todos os profissionais que a utilizam em seu fazer, a exemplo do psicólogo. Pensar e falar na e da escuta não constitui uma novidade no campo da Psicologia, pelo contrário: essa escuta, muitas vezes, acaba sendo relegada a um lugar-comum, como se pudesse ser automatizada tanto na formação profissional quanto na pesquisa, notadamente a que se desenvolve no campo da Psicologia Clínica. Abordar a escuta em um contexto de produção de conhecimento e de formação profissional que a toma como norte e como objeto constitui, portanto, um desafio. Mas de que modo temos pensado a escuta em um programa de pós-graduação? Talvez ouvir esse programa de pós-graduação seja uma tarefa emergente e que tentará ser levada a cabo nesse espaço.

Em 2020 comemoram-se 15 anos do Programa de PósGraduação em Psicologia Clínica e Cultura da Universidade de Brasília (PPGPsiCC-UnB), programa este que tem a sua origem no programa de pós-graduação em Psicologia do Instituto de Psicologia da UnB, datado da década de 1990. Esses 15 anos, desse modo, revelam um tempo consideravelmente maior quando nos propomos a olhar para a consolidação e para o reconhecimento desse programa que visa a formar mestres e doutores comprometidos com a reflexão e o aprimoramento justamente dessa escuta. Uma escuta que não se dá a partir apenas dos ouvidos que podem ser emprestados a um outro em busca de ajuda, de orientação, de presença.

A partir da consideração de um fazer clínico comprometido com a contemporaneidade e a complexidade inerente a essa definição, inclusive, essa escuta passa não mais a ser pensada ou refletida exclusivamente pelas vias sensoriais clássicas da audição, mas a partir de uma corporeidade, incluindo aí os gestos, as expressões, os aromas e os movimentos (Scorsolini-Comin, 2015). A escuta clínica, em uma contemporaneidade impermanente, demanda de nós, profissionais do campo da escuta, essa abertura sensorial, a fim de que novos e potentes sentidos sejam contagiados e promovam significações importantes tanto para os pesquisadores e profissionais que desejamos ser, como pelos pesquisadores, profissionais e docentes com quem podemos partilhar a atividade formativa.

Sabemos que muitos são os desafios da pós-graduação em nosso país, sabemos dos muitos desafios que atravessam 
a área de humanidades, sabemos das especificidades que atingem a Psicologia e, dentro dessas, a miríade de possibilidades - de diálogos e de desafios, consequentemente - em virtude das aproximações entre áreas como a Sociologia, a Filosofia, a Antropologia e a Arte, assumidas como ponto de partida no PPGPsiCC. Tais circunscritores, no entanto, não podem se comprometer com uma lógica que opera no sentido da ruptura, mas justamente na abertura que vislumbra na escuta um caminho para a construção do que pode nos fortalecer enquanto grupo e enquanto indivíduos.

O PPGPsiCC, consciente de sua importância para fomentar esses movimentos não apenas na região CentroOeste do país, mas em todo o Brasil e também em seu constante processo de internacionalização, tem empregado seus conhecimentos e repertórios para disponibilizar aos seus alunos e pesquisadores uma formação condizente com a premissa de que uma clínica não se faz sem uma adequada escuta. De igual monta, um programa de pós-graduação não se estrutura, não se consolida e não se compromete com a sua continuidade sem essa consideração.

Esses 15 anos do PPGPsiCC devem ser rememorados em seus aspectos históricos, em seus personagens e nos itinerários percorridos pelos mesmos para que essa trajetória possa agora ser apreendida com entusiasmo. Reverenciar o passado, a exemplo do que podemos aprender a partir das epistemologias africanas, é um processo de legitimação não apenas do já vivido, mas daquilo que se vislumbra enquanto noção de futuro, de destino, da dimensão que nem sempre podemos controlar. $\mathrm{O}$ número especial que é apresentado pela revista Psicologia: Teoria e Pesquisa, um dos mais importantes periódicos científicos ligados à Psicologia no Brasil, deve ser recebido como um produto que revela não apenas o caminho que se percorreu: mais do que isso, essas narrativas falam de um porvir. Esse futuro emerge como um produto que pode desde já ser apreciado, não na nossa tentativa ocidental de acelerar o tempo, mas de problematizar os ciclos desenvolvimentais que atravessam toda produção de conhecimento e, por isso mesmo, a construção histórica de um programa de pós-graduação. Essas narrativas, mais do que representarem o que pode ser feito por docentes, egressos e atuais mestrandos e doutorandos ao longo desse tempo, permitem que vicejemos os passos futuros.

Assim, esta coletânea deve ser celebrada não apenas como um espaço no qual uma importante produção científica vinculada aos docentes desse programa está sendo compartilhada com a comunidade acadêmica, mas como marco de um período frutífero comprometido com desafios vindouros que podem promover transformações, incrementos e desenvolvimentos vários. A produção científica em nosso país tem atravessado períodos de maior tormenta, sobretudo em um período no qual temos avaliado, nos programas de pós-graduação, quem queremos nos tornar e quais as estratégias que deveremos acionar e desenvolver para cumprir essa tarefa. Isso se faz, inclusive, na costura dos aspectos contextuais, sociais e políticos que ocupam não a periferia do conhecimento, mas justamente a centralidade de nossos investimentos em um programa que se propõe a formar os profissionais que estarão comprometidos com a solidificação desses nossos movimentos e, para além, com os movimentos futuros da pós-graduação.

As pesquisas aqui compartilhadas trazem reflexões, inquietações e perguntas que revelam o comprometimento com que a formação em Psicologia Clínica tem sido corporificada por pesquisadores e pós-graduandos do PPGPsiCC. A diversidade que atravessa as presentes comunicações é emblemática de um movimento contínuo desse grupo no sentido de ampliar e refinar a escuta para diferentes problemáticas atravessadas por elementos sociais e culturais que não ocupam uma posição periférica ou estática de contexto, mas que são trazidos para o epicentro da discussão, permitindo um conhecimento integrado, complexo e que se compromete com o que ainda será narrado.

Essas considerações parecem alinhadas aos desafios descritos há dez anos por Féres-Carneiro et al. (2010), que destacavam a necessidade de, à época, os programas de pós-graduação em Psicologia priorizarem a qualificação/ formação de profissionais para a atuação, o diálogo e a produção do conhecimento no campo das políticas sociais de saúde e de assistência social. O fazer clínico tão bem corporificado pelo PPGPsiCC tem primado por esse diálogo, produzindo nesse percurso uma escuta não apenas como objeto de pesquisa ou recurso interventivo, mas como estratégia para o amadurecimento de seu programa e suas ressonâncias a médio e longo prazos. A partir desse movimento, considera-se que a escuta, por mais tradicional que possa parecer aos profissionais da Psicologia, emerge perenemente como algo inovador.

A narrativa desse futuro, portanto, mobiliza essas produções, assumindo as assimetrias, as disparidades, as dissonâncias e os hiatos como partes daquilo que se pretende integrar, promovendo uma escuta próxima da realidade, situada econômica, social e politicamente (Costa \& Lordello, 2019), prenhe de significações e potências para as transformações que se acenam nos próximos anos - $\mathrm{e}$ que, obviamente, não podemos controlar, sobretudo as que extrapolam os planejamentos de qualquer programa de pós-graduação. Por isso a importância do que permanece, solidificado no modo como compomos a missão de cada programa de pós-graduação e reverenciamos a sua história.

Retomando um dos objetivos do PPGPsiCC, o programa se propõe a "atuar na formação do psicólogo clínico acentuando o espírito investigativo, a multidisciplinaridade, o rigor teórico e a postura crítica e ética necessários à profissão". Esses elementos, basilares de uma formação que se consolida nesses 15 anos (ao menos) de existência, têm permitido não apenas a corporificação de uma escuta inquieta, mas que se coloca à frente, abrindo trincheiras que serão percorridas pelos profissionais em construção. 
Por fim, deve-se destacar que os programas de pósgraduação em Psicologia devem se lançar à escuta do contexto não para anexá-lo a um corpo teórico previamente delimitado, mas para pensar em intervenções e práticas que dialoguem com a comunidade, seus saberes, suas resistências e seus enfrentamentos. Também esse conhecimento pode e deve cada vez mais se descentrar das nossas tradições europeias e norte-americanas, essencialmente brancas e narradas pelos colonizadores, lançando-se, por exemplo, em perspectivas mais afrocentradas ou afrorreferenciadas. Assim, paulatinamente, a escuta do colonizado como objeto de estudo, tantas vezes priorizada na pesquisa científica ocidental e herdeira de um ideário europeu e norte-americano de ciência, poderá ser substituída pela voz do colonizado, narrando as pesquisas que ainda serão construídas e para as quais precisamos nos preparar, refinando nossa escuta.

Quando pensamos na internacionalização, por exemplo, é importante que também nos posicionemos como autores de nossas pesquisas e nossas histórias, recusando o olhar do colonizador que nos explora, nos intimida e nos devasta cientificamente. Inspirados nas proposições do psiquiatra Fanon (2008), há que se propor rupturas que nos assegurem um lugar que subverta o que foi construído e determinado pela colonização. Ao nos internacionalizarmos enquanto programas de pós-graduação, é mister que não mais assumamos a posição de colonizados, mas sim de pesquisadores comprometidos com o amadurecimento e a inovação na pesquisa e na produção do conhecimento a partir de nossas técnicas, de nossas ferramentas, de nossos campos empíricos, de nossos olhares, de nossas escutas e - por que não dizer - de nossas delicadezas.

Mas, no momento em que este texto é veiculado, não podemos nos apartar de uma discussão que justamente tem colocado em xeque o presente e o futuro, em uma perspectiva global e que marcará todo o século XXI. A pandemia causada pelo novo coronavírus (SARS-CoV-2), deflagrada pela Organização Mundial da Saúde em 2020, tem promovido profundas mudanças em todas as dimensões da vida (Kola, 2020; Ornell et al., 2020), suspendendo, em diversos momentos, as noções sobre o futuro e o que poderá ser escrito após esse fenômeno. Diferentes inteligibilidades têm sido convocadas para refletir sobre as repercussões inequívocas da pandemia nos mais diversos setores da vida, entre eles a educação e a própria atuação no campo da saúde mental a partir desse evento global.

A instabilidade dos marcadores temporais, agora abalados pela pandemia, com certeza será um atravessador do modo como os programas de pós-graduação e a própria ciência psicológica se posicionarão diante do que deverá ser reconstruído, diante do que deverá ser abandonado e diante do que deverá ser criado não apenas para oferecer respostas, mas também perspectivas. Retomando os argumentos aqui defendidos, esses movimentos orientados "para frente" não poderão ser tecidos sem a reverência ao passado, tornando premente o ir-e-vir para a compreensão do que, de fato, poderá ser. Esse desafio, para além das transformações várias e que ainda se mostram em trânsito, não nos permitindo uma análise mais pormenorizada, pode justamente se valer da potência da escuta e da delicadeza, como aqui narrado.

Penso que a narrativa do futuro na pós-graduação em Psicologia só será possível a partir da emergência e da corporificação dessas delicadezas que nos constituem perenemente. Aventando que esses elementos possam ser avivados nesse momento de maior instabilidade, eles também nos ajudam a pensar no futuro de modo mais consciente, menos afoito e mais tolerante para o que não podemos nunca controlar, o que não nos exime da responsabilidade que se assenta em nosso fazer como profissionais da escuta. Esse movimento pode nos tornar mais atentos àquilo que, de fato, pode compor inovações que nos permitam avançar, preocupados com as novas escutas e as novas sensorialidades convocadas pelo humano e seus desafios. Que esse porvir seja, de fato, narrado, e que o futuro se teça com uma atitude de cuidado, "com delicada curiosidade, atenta à fome e à própria atenção" (Lispector, 1999, p. 220).

\section{REFERÊNCIAS}

Bastos, A. V. B., Tomanari, G. Y., Trindade, Z. A., \& Andery, M. A. P. A. (2015). The Psychology postgraduate system in Brazil: Current characteristics and challenges for the area. Psicologia: Reflexão e Crítica, 28, 23-33. https://doi.org/10.1590/16787153.2015284005

Costa, A. L. F., Coelho-Lima, F., Costa, J. P., Seixas, P. S., \& Yamamoto, O. H. (2014). Internacionalização da pósgraduação em Psicologia: Estudo comparativo dos cursos de doutorado no Brasil e na Espanha. Revista Brasileira de PósGraduação, 11(25), 789-818. https://doi.org/10.21713/23582332.2014.v11.548

Costa, A. L. F., \& Yamamoto, O. H. (2017). 50 anos de pósgraduação stricto sensu de Psicologia no Brasil. Memorandum, 31, 133-160.

Costa, P. H. A., \& Lordello, S. R. (2019). Psicologia e realidade brasileira: Notas preliminares para uma práxis psicossocial.
In C. Antloga, K. T. Brasil, S. R. Lordello, M. Neubern, \& E. Queiroz. (Orgs.), Psicologia clínica e cultura contemporânea 4 (pp. 3-16). Tecnopollitik.

Fanon, F. (2008). Pele negra, máscaras brancas (R. Silveira, trad.). EDUFBA. (Originalmente publicado em 1952) https://doi. org/10.7476/9788523212148

Féres-Carneiro, T., Bastos, A. V., Feitosa, M. A. G., Seidl-deMoura, M. L., \& Yamamoto, O. (2010). Lacunas, metas e condições para a expansão da pós-graduação em psicologia no país. Psicologia: Reflexão e Crítica, 23, 11-24. https://doi. org/10.1590/S0102-79722010000400003

González Rey, F. (2007). Psicoterapia, subjetividade e pósmodernidade: Uma aproximação histórico-cultural. Thomson Learning. 
Kola, L. (2020). Global mental health and COVID-19. The Lancet Psychiatry, 7(8), 655-657. https://doi.org/10.1016/S22150366(20)30235-2

Lima, R. F. F., \& Morais, N. A. (2019). Subjective well-being profiles of street involved youth: A longitudinal analysis based on clusters. Universitas Psychologica, 18(2), 1-11. https://doi. org/10.11144/Javeriana.upsy18-2.swbp

Lispector, C. (1999). A descoberta do mundo. Rocco.

Lordello, S. R., \& Costa, L. F. (2017). Intervenção grupal com mulheres cuja gravidez decorreu de violência sexual: Uma leitura construcionista social. Nova Perspectiva Sistêmica, 59, 52-70.

Morin, E. (2000). Ciência com consciência. Bertrand.

Nobles, W. (2009). Seeking the Sakhu - Foundational writings for an African Psychology. Third Word Press.

Nogueira, S. G., \& Guzzo, R. S. L. (2016). Psicologia Africana: Diálogos com o sul global. Revista Brasileira de Estudos Africanos, 1(2), 197-218. https://doi.org/10.22456/24483923.66828

Ornell, F., Schuch, J. B., Sordi, A. O., \& Kessler, F. H. P. (2020). "Pandemic fear" and COVID-19: Mental health burden and strategies. Brazilian Journal of Psychiatry, 42(3), 232-235. https://doi.org/10.1590/1516-4446-2020-0008

Ribeiro, R. I., Salami, S., \& Diaz, R. B. C. (2004). Por uma psicoterapia inspirada nas sabedorias negro-africana e antroposófica. In V. A. Angerami-Camon (Org.), Espiritualidade e prática clínica (pp. 85-110). Thomson.

Rossetti-Ferreira, M. T., Sólon, L. A. G., \& Almeida, I. G. (2010). A delicada arte da conversa e da escuta. In D. C. F. Bernardi (Coord.), Cada caso é um caso: Estudos de caso, projetos de atendimento (pp. 61-73). Associação Fazendo História/ NECA - Associação dos Pesquisadores de Núcleos de Estudos e Pesquisas sobre a Criança e o Adolescente.

Scorsolini-Comin, F. (2015). Um toco e um divã: Reflexões sobre a espiritualidade na clínica etnopsicológica. Contextos Clínicos, 8(2), 114-127. https://doi.org/10.4013/ctc.2015.82.01

Souza, L. V., \& Scorsolini-Comin, F. (2017). Aprendizagem colaborativa no ensino superior: Experiências costuradas pelo diálogo. In M. Grandesso (Org.), Práticas colaborativas e dialógicas em distintos contextos e populações: Um diálogo entre teoria e práticas (pp. 655-671). CRV. 